\title{
Математические исследования траектории полета капли жидкости
}

\author{
Л.Г. Нетецкий, Н.П. Артёмов, А.Д. Калюжный ${ }^{1}$, И.Р. Ростовский \\ Харьковский национальный университет сельского хозяйства \\ имени Петра Василенко (г.. Харьков, Украина) \\ email: ${ }^{1}$ aleksandrkaluzhnij@gmail.com; ORCID: ${ }^{1}$ 0000-0001-5587-6606
}

\begin{abstract}
Важной операцией сельскохозяйственных машин, обслуживающих растениеводство, является внесение жидких химикатов. С качественным соблюдением нормы их внесения. Работа относится к новациям в области сельскохозяйственного машиностроения и посвящена исследованию центробежного способа поверхностного внесения жидких химикатов. Экспериментальные исследования центробежного разбрызгивателя, который выполнен в виде полузакрытой тарелки с вертикальным цилиндрическим бортом подтвердило его работоспособность. Использование гравитационной подачи и дозирование жидкости целесообразно при внесении малых доз химикатов, которое в свою очередь, имеет эксплуатационные и технологические преимущества в сравнении с традиционными при поверхностном способе внесения жидких химикатов. Конструкция тарельчатого разбрызгивателя исключает необходимость использования насосов высокого давления и вентиляторных устройств, которые используются в существующих распылителях. Поступая во внутреннюю полость тарелки, рабочая жидкость под действием центробежной силы располагается кольцевым слоем по внутренней поверхности. Попадая в сопло, жидкость прижимается к задней стенке сопла, приобретая одинаковую с тарелкой окружную скорость. На выходе из сопла скорость жидкости складывается из окружной и радиальной составляющих. Начальная скорость жидкости на входе в канал определяется окружной скоростью тарелки, толщиной слоя и плотностью жидкости. Факел распыленной жидкости для соплового элемента определяется частотой вращения тарелки, а также числом и производительностью сопел. Определенные экспериментальным путем параметры пятна распыла использовались как исходные данные для математической оценки траектории полета капли. Было установлено что на дальность полета капли влияет сопротивление воздушной среды, частота оборотов разбрызгивающего диска, высота его установки от уровня земли а так же наклон сопел.
\end{abstract}

Ключевые слова: тарелка разбрызгивания, угол наклона сопел, гравитационная подача, пятно распыла, траектория полета, капля, уравнение, тангенциальная скорость, радиальная скорость, масса частицы

Целью данной работы была математическая оценка траектория полета капли жидкости от конструктивных параметров диска разбрызгивания. Таких как высоты его расположения над землей, угловой скорости, давления жидкости внутри диска ,а также влияния на дальность полета капли сопротивления воздушной среды.

Исходными данными для математических исследований является разработка центробежного разбрызгивателя. Результаты практических исследований подтвердили работоспособность устройства и показали зависимость качества работы от вышеуказанных параметров.

Результаты исследований подтвердили работоспособность тарельчатый разбрызгиватель жидких химикатов.

Тарелка расположена на высоте Н от поверхности земли (рис.1).

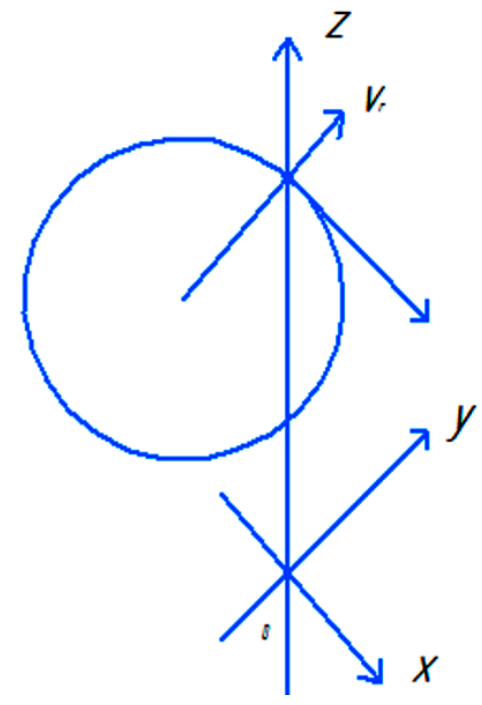

Рис.1 Траектория полета капли в координатах 
Траекторию полета капли определяется следующей системой уравнений:

$$
\left\{\begin{array}{c}
m x^{\prime \prime}{ }_{t}=k x_{t}^{\prime} \\
m y_{t}^{\prime \prime}=k y_{t}^{\prime} \\
m z_{t}^{\prime \prime}=m f-k z_{t}^{\prime}
\end{array}\right.
$$

С начальными условиями:

$$
\begin{gathered}
x(0)=0 y(0)=0 z(o)=\mathrm{H} \\
x^{\prime}(0)=v_{k} y^{\prime}(0)=v_{r} z^{\prime}(0)=0
\end{gathered}
$$

где: $v_{k}-$ тангенциальная скорость которая зависит от угловой скорости диска, м/с; $v_{r}$ - радиальная скорость которая зависит от давлення жидкости внутри диска, м/с.

Так уравнения, входящие в систему независимы сначала решаем первое уравнение:

$$
m x_{t}^{\prime \prime}+k x_{t}^{\prime}=0
$$

Записываем характеристическое уравнение:

$$
m p^{2}+k p=0
$$

Корни характеристического уравнения равны.

$$
p_{1}=0 p_{2}=-\frac{k}{m}
$$

Получим общее решение:

$$
\begin{aligned}
& X(t)=C_{1}+C_{2} e^{-\frac{k}{m} t} \\
& X^{\prime}(t)=-\frac{C_{2} k}{m} e^{-\frac{k}{m} t}
\end{aligned}
$$

Для $\mathrm{C}_{1}$ и $\mathrm{C}_{2}$ учаем систему:

$$
\left\{\begin{array}{l}
\mathrm{C}_{1}+\mathrm{C}_{2}=0 \\
-\frac{\mathrm{C}_{2 K}}{m}=v_{K}
\end{array}\right.
$$

Получим

$$
\mathrm{C}_{2}=-\frac{k}{m} v_{r} \text { и } \mathrm{C}_{1}=\frac{k}{m} v_{K}
$$

С учетом начальных условий для тангенциальной скорости получаем:

$$
x(t)=\frac{m}{k} v_{K}\left(1-e^{-\frac{k}{m} t}\right)
$$

Обозначим

$$
\frac{k}{m}=B
$$

Тогда:

$$
x(t)=\frac{v_{k}}{B}\left(1-e^{-B t}\right)
$$

Аналогично для радиальной скорости получим:

$$
y(t)=\frac{v_{r}}{B}\left(1-e^{-B t}\right)
$$

Решаем третье уравнение:

$$
\begin{gathered}
z_{t}^{\prime \prime}=-g-\frac{k}{m} z_{t}^{\prime} \\
z_{t}^{\prime \prime}+\frac{k}{m}{ }^{\prime}=-g \\
p^{2}+\frac{k}{m} p=c \\
p=0 p=-\frac{k}{m} \\
z_{\text {он }}(t)=c_{1}+c_{2} e^{-\frac{k}{m}} \\
z_{r . \text { н. }}=A t z_{2 . u}^{\prime}=A
\end{gathered}
$$

Поставляя в третье уравнение системы (1) получаем:

$$
\frac{k}{m} A=-g ; A=-\frac{g m}{k} .
$$

И для $z(t)$ получаем:

$$
\begin{aligned}
& z(t)=c_{1}+c_{2} e^{-\frac{k}{m} t}-\frac{m g}{k} t \\
& z^{\prime}(t)=-\frac{k}{m} c_{2} e^{-\frac{k}{m} t}-\frac{m g}{k}
\end{aligned}
$$

С учетом начальных условий получаем систему:

$$
\left\{\begin{array}{c}
\mathrm{c}_{1}+\mathrm{c}_{2}=H \\
-\frac{k c_{2}}{m}-\frac{m g}{k}=0
\end{array}\right.
$$

Или

$$
\mathrm{c}_{1}=H+\frac{m^{2} g}{k^{2}} ; \mathrm{c}_{2}=-\frac{m^{2} g}{k^{2}}:
$$

Окончательным для $z(t)$ получаем:

$$
z(t)=H+\frac{m^{2} f}{k^{2}}-\frac{m^{2} f}{k^{2}} e^{-\frac{k}{m} t}-\frac{m f}{k} t
$$

или учитываем что

$$
\frac{k}{m}=B ;
$$

Коэффрициент сопротивления потока частиц

$$
B=\frac{k}{m} ;
$$

где $m$ - масса частицы:

Имеем:

$$
z(t)=H+\frac{g}{B^{2}}\left(1-e^{-B t}\right)-\frac{g t}{B}
$$

Для определения дальности полета капли нам необходимо определить время падения капли, которое получим решив уравнение:

$$
z\left(t_{\Pi}\right)=0
$$


Или:

$$
H+\frac{g}{B^{2}}\left(1-e^{-B t_{\Pi}}\right)-\frac{g t_{\Pi}}{B}=0
$$
дами:

Которое можно решить численными мето-

$$
y\left(t_{n}\right)
$$

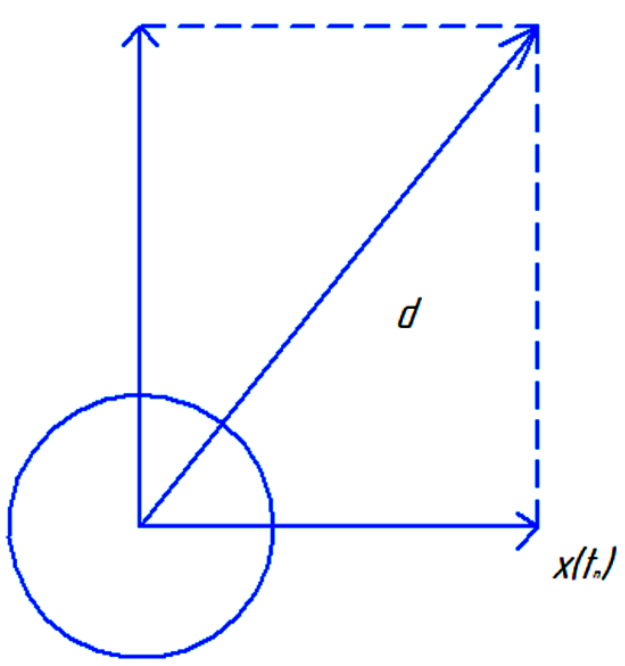

Рис.2 Проекция троектории полета капли.

Записываем формулу для дальности полета:

$$
d \cong \sqrt{x^{2}\left(t_{\Pi}\right)+y^{2}\left(t_{\Pi}\right)}
$$

Учитывая формулы (2) и (3) для $\mathrm{x}(\mathrm{t})$ и $\mathrm{y}(\mathrm{t})$ получим:

$$
d \cong \frac{1}{B}\left(1-e^{-B t_{\Pi}}\right) \sqrt{v_{k}^{2}+v_{r}^{2}}
$$

Выразим $1-e^{-B t_{\text {п }}}$ из условия

$$
\begin{gathered}
H+\frac{g}{B^{2}}\left(1-e^{-B t_{\Pi}}\right)-\frac{g t_{\Pi}}{B}=0: \\
1-e^{-B t_{\Pi}}=\left(\frac{g t_{\Pi}}{B}-H\right) * \frac{B^{2}}{g} \\
1-e^{-B t_{\Pi}}=\left(t_{\Pi}-\frac{H B}{g}\right) B
\end{gathered}
$$

Тогда дальность полета капли выражается формулой

$$
d \approx\left(t_{\Pi}-\frac{H B}{g}\right) \sqrt{v_{k}^{2}+v_{r}^{2}}
$$

где $t_{\text {п }}$ время колебания капли, с; $H$ - высота расположения диска над землей, м; $B$ - коэффициент сопротивления потока частиц; $g$ - ускорения свободного падения, м/с; $v_{k}$ - тангенциальная скорость которая зависит от угловой скорости диска, м/с; $v_{r}$ - радиальная скорость которая зависит от давлення жидкости внутри диска, м/с.

\begin{tabular}{|c|c|c|c|c|c|c|c|c|c|}
\hline 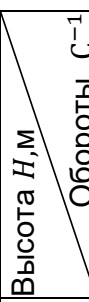 & প্ল & $\stackrel{m}{m}$ & 움 & ! & டㅇ & 员 & 8 & $\stackrel{8}{6}$ & 운 \\
\hline 0,60 & 1,87 & 1,91 & 1,95 & 1,98 & 2,01 & 2,05 & 2,08 & 2,11 & 2,14 \\
\hline 0,65 & 1,93 & 1,95 & 2,06 & 2,10 & 2,14 & 2,17 & 2,21 & 2,24 & 2,27 \\
\hline 0,70 & 1,98 & 1,99 & 2,18 & 2,22 & 2,27 & 2,31 & 2,34 & 2,38 & 2,41 \\
\hline 0,75 & 2,02 & 2,04 & 2,30 & 2,34 & 2,41 & 2,45 & 2,49 & 2,52 & 2,56 \\
\hline 0,80 & 2,06 & 2,08 & 2,43 & 2,46 & 2,55 & 2,59 & 2,64 & 2,68 & 2,72 \\
\hline 0,85 & 2,08 & 2,14 & 2,55 & 2,59 & 2,71 & 2,75 & 2,80 & 2,84 & 2,88 \\
\hline 0,90 & 2,10 & 2,19 & 2,68 & 2,72 & 2,87 & 2,91 & 2,97 & 3,02 & 3,06 \\
\hline 0,95 & 2,11 & 2,25 & 2,80 & 2,86 & 3,03 & 3,08 & 3,16 & 3,20 & 3,25 \\
\hline 1,00 & 2,11 & 2,25 & 2,81 & 2,87 & 3,05 & 3,13 & 3,20 & 3,26 & 3,32 \\
\hline
\end{tabular}

Полученные формулы дают возможность рассчитать дальность рассеивания в зависимости от конструктивных параметров. Результаты расчетов приведены в таблице

Таблица1. Дальность полета капли $(d$, м.) В зависимости от оборотов разбрызгиватели и его высота расположения.

Выводы:

1. Дальность полета капли зависит: от высоты расположения диска над землей, тангенциальной и радиальной скорости его вращения, коэффициента сопротивления полета капли.

2. С увеличением высоты от 0,65 до 1 м расположения диска над землей дальность полета капли увеличивается в приделах от 1,12 до 1,55 раза.

3. Изменение числа оборотов диска от 30 до 70 с-1 увеличивает дальность разбрызгивания в диапазоне от 1,14 до 1,57 раза.

\section{Література:}

1. Калюжный, А.Д., Ридный, Р.В. Меджидов, Р.Р. (2010) 'Устройство для внесения жидких минеральных удобрений с гравитационным дозированием', Вісник ХНТУСГ ім. П. Василенка, 103, c. $108-111$.

2. Калюжный, А. Д. и др. (2012) 'Дослідження роботи дозуючого пристрою для внесення малих доз рідких хімікатів', Вісник ХНТУСГ ім. П. Василенка, 124, сс. 48-52. 
3. Калюжный, А.Д. и др. (2019) 'експериментальне дослідження відцентрового розприскувача рідких хімікатів', Харківський національний технічний університет сільського господарства імені Петра Василенка.

4. Пажи, Д. Г., Галустов, В. С. (1984) Процессы и аппараты химической и нефтехимической технологии. Основы техники распыливания жидкостей-М:, Основы техники распыливания жидкостей-М: Химия.

\section{References:}

1. Kalyuzhnyiy, A.D., Ridnyiy, R.V. and Medzhidov, R.R. (2010) 'Ustroystvo dlya vneseniya zhidkih mineralnyih udobreniy $s$ gravitatsionnyim dozirovaniem', VIsnik HNTUSG Im. P. Vasilenka, 103, pp. 108-111.

2. Kalyuzhnyiy, A.D. et al (2012) 'Doslldzhennya roboti dozuyuchogo pristroyu dlya vnesennya malih doz rldkih hlmlkatlv', VIsnik HNTUSG Im. P.Vasilenka, 124, pp. 48-52.

3. Kalyuzhnyiy, A.D. i dr. (2019) 'Eksperimentalne doslidzhennya vidtsentrovogo rozpriskuvacha ridkih himikativ', Harklvskiy natslonalniy tehnlchniy unlversitet sllskogo gospodarstva Imenl Petra Vasilenka.

4. Pazhi, D.G. and Galustov, V.S. (1984) Protsessyi i apparatyi himicheskoy i neftehimicheskoy tehnologii Osnovyi tehniki raspyilivaniya zhidkostey - M:, Osnovyi tehniki raspyilivaniya zhidkostey $-\mathrm{M}$ : Himiya.

Анотація

\section{Математичні дослідження траєкторії польоту краплі рідини}

\section{Л.Г. Нетецькій, М.П.Артьомов, О.Д. Калюжний, І.Р. Ростовський}

Важливою операцією сільськогосподарських машин, що обслуговують рослинництво, $є$ внесення рідких хімікатів (добрив, пестицидів, гербіцидів і ін.), 3 якісним дотриманням норми їх внесення. Робота відноситься до новацій в галузі сільськогосподарського машинобудування та присвячена дослідженню відцентрового способу поверхневого внесення рідких хімікатів.

Експериментальні дослідження відцентрового розпилювача, який виконаний у вигляді напівзакритої тарілки з вертикальним циліндричним бортом підтвердило його працездатність. Використання гравітаційної подачі і дозування рідини доцільно при внесенні малих доз хімікатів, яке в свою чергу, має експлуатаційні та технологічні переваги в порівнянні з традиційними при поверхневому способі внесення рідких хімікатів. Конструкція тарельчатого розбризкувача виключає необхідність використання насосів високого тиску і вентиляційних пристроїв, які використовуються в існуючих розпилювачі. Поступаючи у внутрішню порожнину тарілки, робоча рідина під дією відцентрової сили розташовується кільцевим шаром по внутрішній поверхні. Потрапляючи в сопло, рідину притискається до задньої стінки сопла, набуваючи однакову з тарілкою окружну швидкість.

На виході з сопла швидкість рідини складається з окружної та радіальної складових. Початкова швидкість рідини на вході в канал визначається окружною швидкістю тарілки, товщиною шару і щільністю рідини. Факел розпорошеної рідини для соплового елемента визначається частотою обертання тарілки, а також числом і продуктивністю сопел. Певні експериментальним шляхом параметри плями розпилу використовувалися як вихідні дані для математичної оцінки траєкторії польоту краплі. Було встановлено що на дальність польоту краплі впливає опір повітряного середовища, частота обертів розпилювального диска, висота його установки від рівня землі а так же нахил сопел.

Ключові слова: тарілка розбризкування, кут нахилу сопел, гравітаційна подача, пляма розпилу, траєкторія польоту, крапля, рівняння, тангенціальна швидкість, радіальна швидкість, маса частинки

\section{Abstract}

\section{Mathematical studies of the flight path of a liquid drop}

\section{L.G. Netetskiy, N.P.Artiomov, A.D. Kalyuzhny, I.R. Rostovskiy}

An important operation of agricultural machinery, which provides maintenance services, $\epsilon$ the introduction of rare chemicals (kind, pesticides, herbicides and in.), With the requirements of the application. The robot is introduced to the innovations in the galuzi of the Silk-Gospodar machine-building and is assigned to the precenter method of surface introduction of wild chemicals.

Experimental advancement of a center-mounted razpilyuvach, such as a vykoniy at the viglyadi of a closed container with a vertical cylindrical board, confirmed its approval. Victory of gravitational supply and addition of a dose of chemistry with small doses of chemicals, like in its own swindle, little exploitation and technological 
upgrades in accordance with traditional methods with surface methods of chemical introduction. The design of a bowl-shaped razorbizkuvach viklyucha the need for pumping in a high vice and ventilation annexes, as a vikoristovy in izuyuchi raspiluvachi. Proceeding from the inner empty tare, the work is carried out by means of a circular force on the inner surface with a ball on the inner surface.

Drinking into the nozzle, press down to the back of the nozzle, filling the same with the container around the nozzle. At the outlet from the nozzle, the speed of the line is stored from the circular and radio warehouse. Pochatkova shvidk_styu ridini at the entrance to the channel begins with the district shvidkistyu tarilka, tovschina ball and brilliant ridini. The torch of the rosé line for the nozzle element is based on the frequency of wrapping of the container, as well as the number and productivity of the nozzles. Singing with an experimental path of parameters, with the help of a saw-cut vikorist, they were used as the original data for a mathematical assessment of the trajectory of the polot krapli. It was found that the range of the drop is influenced by the resistance of the air environment, the frequency of revolutions of the spray disc, the height of its installation from the ground level, as well as the inclination of the nozzles.

Keywords: spray plate, nozzle tilt angle, gravity feed, spray pattern, flight path, drop, equation, tangential velocity, radial velocity, particle mass

\section{Бібліографічне посилання/ Bibliography citation: Harvard}

Netetskiy, L. G., et al. (2020) 'Mathematical studies of the flight path of a liquid drop', Engineering of nature management, (3(17), pp. 81 - 85.

Подано до редакції / Received: 08.09.2020 